\title{
The influence of welding parameters on macrostructure and mechanical properties of Sc-modified AA2519-T62 FSW joints
}

\author{
Robert Kosturek*, Lucjan Śnieżek, Janusz Torzewski, and Marcin Wachowski \\ Faculty of Mechanical Engineering, Military University of Technology, 2 gen. S. Kaliskiego St., 00-908 Warsaw, Poland
}

Received: 6 May 2020 / Accepted: 1 August 2020

\begin{abstract}
In this investigation, a $5 \mathrm{~mm}$ thick extrusion of AA2519-T62 alloy has been welded using friction stir welding method. The various sets of process parameters have been involved within the range of 400-1200 rpm tool rotation speed and $100-800 \mathrm{~mm} / \mathrm{min}$ welding speed. Selected joints have been subjected to the macrostructure analysis, microhardness measurements, tensile and low cycle fatigue testing (at $\varepsilon=0.3 \%$ ), and fractography analysis. It has been stated that imperfection-free macrostructure is obtained for welds produced with lowest welding speed: $100 \mathrm{~mm} / \mathrm{min}$ and tool rotation speed within the range of $400-800 \mathrm{rpm}$. The highest joint efficiency ( $85 \%$ ) has been obtained for the sample characterized by the presence of voids in the upper part of the stir zone. Considering macrostructure analysis and established mechanical properties of the joints, it may be concluded that the best set of welding parameters for AA2519-T62 is within the range of 600-800 rpm tool rotation speed with welding speed of $100 \mathrm{~mm} / \mathrm{min}$ for used MX Triflute tool.
\end{abstract}

Keywords: Friction stir welding / mechanical properties / AA2519 / aluminum alloy / welding parameters / fatigue / fractography

\section{Introduction}

Friction stir welding (FSW) allows to produce a highquality joint of precipitation-hardened aluminum alloys including $\mathrm{Al}-\mathrm{Cu}$ based alloys for the temperature of the joining process is lower than $\mathrm{Al}-\mathrm{Cu}$ eutectic melting point [1-3]. FSW, despite its advantages (such as low energy consumption and neutrality for the environment), requires a proper set of welding parameters: tool geometry, tool rotation speed, welding speed and force (or plunge depth) in order to obtain a defect-free join with as high as possible joint efficiency [4-6]. In the case of aluminum alloys having a high concentration of copper (e.g. AA2219, AA2519), the major problem is the losses in the participation of the strengthening phase (overaging, dissolution, coarsening) due to heat generated during FSW process $[4,7,8]$. Although, this phenomenon cannot be avoided for heat is needed for the plasticization of welded material, the proper selection of welding parameters allows to limit the generation of heat, providing only the minimum amount required for the formation of a high-quality joint [9]. In recent years, several investigations have focused on the optimization of welding parameters for AA2219 and

\footnotetext{
*e-mail: robert.kosturek@wat.edu.pl
}

AA2519 alloys, including various cooling conditions [7,10-14]. Sabari et al. investigated FSW and underwater friction stir welding (UWFSW) of $6 \mathrm{~mm}$ thick AA2519-T87 with various tool rotation speeds and reported the highest joint efficiency of $62 \%$ for FSW and $82 \%$ for UWFSW [10]. Liang et al. focused on the microstructure of friction stir welded $10 \mathrm{~mm}$ thick AA2519-T87 providing data of the evolution of strengthening phase in the joint zones explaining the decreases in microhardness [7]. Ubaid et al. reported a joint efficiency of $75 \%$ for friction stir welded $15.4 \mathrm{~mm}$ thick AA2519-T87 with the failure location in the thermo-mechanically affected zone/heataffected zone (TMAZ/HAZ) interface on the retreating side of the weld [11]. Some information about properties of friction stir welded AA2519 can be received from investigations concerned with friction stir welding of AA2219, which is a precursor of AA2519. Zhang et al. investigated influence of FSW process parameters on properties of $5.6 \mathrm{~mm}$ thick AA2219-T6 joints and reported that optimal welding parameters consist within the range of 400-800 rpm tool rotation speed for welding speed of $100-800 \mathrm{~mm} / \mathrm{min}$ and that the lowest hardness zone (LHZ) can be localized at the nugget zone (NZ)/TMAZ interface, at the TMAZ or at HAZ depending on used parameters [12]. Liu at al. performed research on the influence of parameters on properties of $7.5 \mathrm{~mm}$ thick AA2219-T6 FSW joint, with rotation speed range and the welding speed 
Table 1. Chemical composition of AA2519 [\% weight].

\begin{tabular}{|c|c|c|c|c|c|c|c|c|c|c|c|}
\hline $\mathrm{Fe}$ & $\mathrm{Si}$ & $\mathrm{Cu}$ & $\mathrm{Zn}$ & $\mathrm{Ti}$ & $\mathrm{Mn}$ & $\mathrm{Mg}$ & $\mathrm{Ni}$ & $\mathrm{Zr}$ & $\mathrm{Sc}$ & $\mathrm{V}$ & $\mathrm{Al}$ \\
\hline 0.11 & 0.08 & 6.32 & 0.05 & 0.08 & 0.17 & 0.33 & 0.02 & 0.19 & 0.16 & 0.10 & Base \\
\hline
\end{tabular}

Table 2. Mechanical properties of AA2519-T62.

\begin{tabular}{llll}
\hline Young modulus $(E)$ & Yield strength $\left(R_{\mathrm{e} 0,2}\right)$ & Tensile strength $\left(R_{m}\right)$ & Elongation $(A)$ \\
\hline $78 \mathrm{GPa}$ & $312 \mathrm{MPa}$ & $469 \mathrm{MPa}$ & $19 \%$ \\
\hline
\end{tabular}

in the range of $300-1000 \mathrm{rpm}$ and $50-400 \mathrm{~mm} / \mathrm{min}$, respectively and reported that the highest joint efficiency (79\%) has been achieved for joint obtained with parameters of $800 \mathrm{rpm}$ and $200 \mathrm{~mm} / \mathrm{min} \mathrm{[13].} \mathrm{Xu} \mathrm{et} \mathrm{al.}$ investigated low-cycle fatigue (LCF) of a friction stir welded $6 \mathrm{~mm}$ thick 2219-T62 at different welding parameters and cooling conditions and stated that fatigue lifetime slightly decreased with increasing welding speed from 60 to $200 \mathrm{~mm} / \mathrm{min}$, but they were nearly independent of the rotational rate between 300 and $1000 \mathrm{rpm}$ [14]. Several investigations have been dedicated to FSW of scandiummodified aluminum alloys, showing that it influences the formation of the joint by improving grain refinement in the stir zone due to nano-sized $\mathrm{Al}_{3} \mathrm{Sc}$ dispersoids that increases the mechanical properties of the weld [15-17]. Additionally, scandium reduces the grain growth in the heat-affected zone, what also improves the overall strength of the joint [18-20]. The influence of welding parameters properties of friction stir welded armor grade AA2519 and Sc-modified 2XXX series is still a major gap in the current state of the art. This paper aims to investigate the influence of tool rotation speed $(400-1200 \mathrm{rpm})$ and welding speed $(100-800 \mathrm{~mm} / \mathrm{min})$ on the basic properties of AA2519-T62 friction stir welded joints.

\section{Materials and methods}

The material to be weld was $5 \mathrm{~mm}$ thick AA2519-T62 extrusion with dimensions of $80 \times 250 \mathrm{~mm}$. The chemical composition and mechanical properties of the alloy are presented in Tables 1 and 2, respectively.

Before the welding, the surfaces of workpieces have been ground and cleaned with isopropyl alcohol. The friction stir welding process was performed by using ESAB FSW Legio 4UT machine with an axial force equals to 17 $\mathrm{kN}$ and the tilt angle of MX Triflute tool set to $2^{\circ}$. For tool rotation and welding speed, the various sets of welding parameters have been used, described in the further part of the investigation. Basing on the surface morphology of obtained joints, the set of welds has been selected for further analysis. In order to perform macrostructure analysis, the samples were cut perpendicular to the welding direction (cross-welds) then prepared according to the standard metallographic techniques for specimen preparation. Their microstructure has been revealed using Keller reagent $\left(20 \mathrm{~mL} \mathrm{H}_{2} \mathrm{O}+5 \mathrm{~mL} \mathrm{HNO}_{3}+1 \mathrm{~mL} \mathrm{HF}+\right.$ one drop

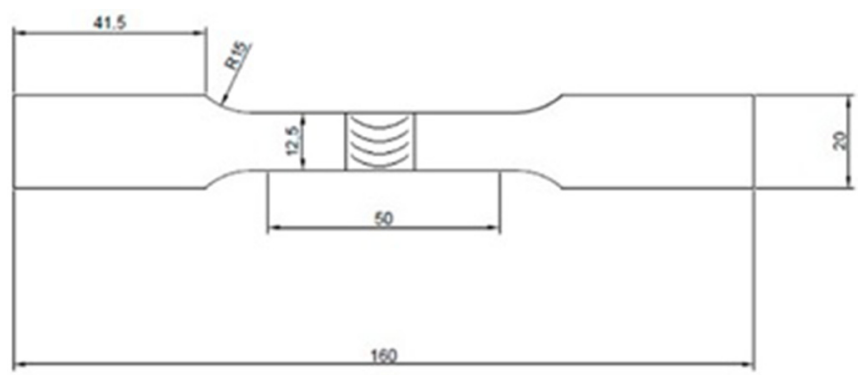

Fig. 1. Scheme of sample for tensile testing.

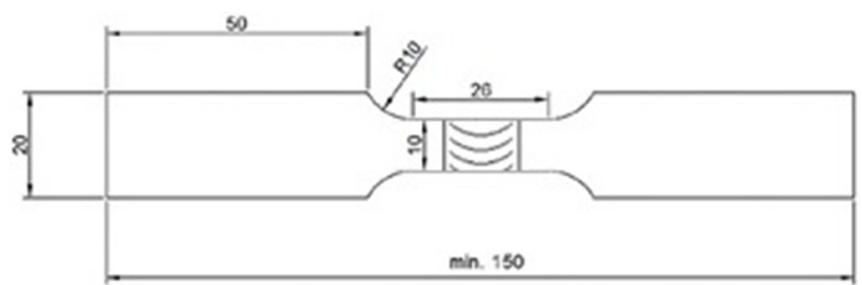

Fig. 2. Scheme of sample for low-cycle fatigue testing.

of $\mathrm{HCl}$ ) with etching time equal to $10 \mathrm{~s}$. The macrostructure observations have been performed using a digital light microscope Olympus LEXT OLS 4100. The Vickers microhardness of the welds has been measured on the cross-section of the polished sample by applying a load of $0.98 \mathrm{~N}$ according to EN ISO 6507 standard. The mechanical properties of the joints were examined by tensile testing on INSTRON 8802 MTL universal testing machine with WaveMatrix computer software according to ASTM standard E8/E8M-13a. For each joint three tensile tests were carried out. The LCF tests were carried out according to ISO 12106:2017 in a fully reversed total strain-controlled condition $(R=0.1)$ with a strain amplitude of $0.3 \%$. Also, in this case three samples were investigated for each joint. For tensile and fatigue testing the samples have been prepared with geometry presented in Figures 1 and 2, respectively.

All types of samples have been cut from the central part of the welded plates with a minimum distance of $20 \mathrm{~mm}$ from the start and end point of the weld line. The microhardness measurements, tensile and fatigue tests were carried out 4 weeks after the welding process for properties of the joint to stabilize. The fracture surfaces of the tensile and fatigue samples of selected joints have been 


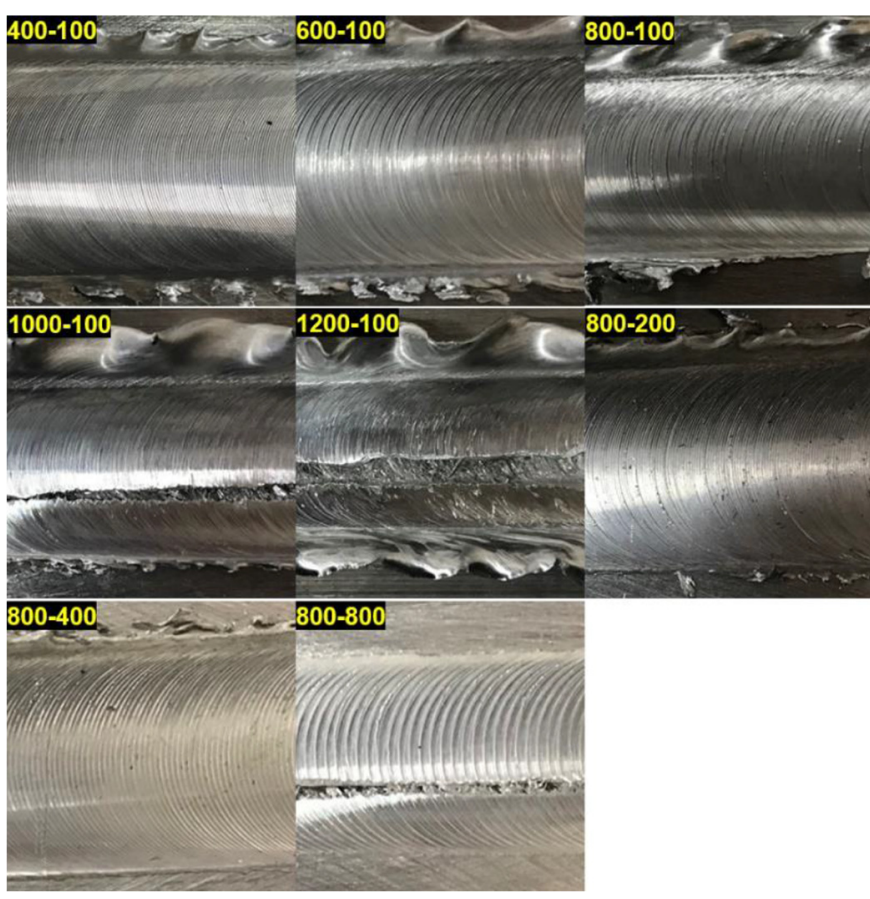

Fig. 3. Surface morphologies of FSW joints from the face side with different welding process parameters designed: [tool rotation speed in $\mathrm{rpm}$ ] - [welding speed in $\mathrm{mm} / \mathrm{min}$ ].

investigated using scanning electron microscope (SEM) Jeol JSM-6610.

\section{Results and discussion}

\subsection{Welding process and sample selection}

The friction stir welding process has been realized with five different values of tool rotation speed: 400, $600,800,1000$, and $1200 \mathrm{rpm}$ with a constant value of $100 \mathrm{~mm} / \mathrm{min}$ welding speed. It has been observed that increasing rotation speed above $800 \mathrm{rpm}$ leads to the formation of tunnel imperfection in the joint. The reason for this is the overheating of the welded material entailing the too high plasticization and throwing the plasticized material by the rotating tool outside the stirring region with the formation of the flash on the retreating side of the weld. For the highest value of $800 \mathrm{rpm}$, which allowed to produce a joint with the face side without visual imperfections, the further welding processes have been performed with higher values of welding speed: 200,400 , and $800 \mathrm{~mm} / \mathrm{min}$. The first two values have formed the good weld face with noticeable lower flash at the retreating side of joints comparing to the samples obtained with $100 \mathrm{~mm} / \mathrm{min}$ welding speed. Additionally, it has to be taken under consideration that it is not excluded to produce a good quality joint using higher rotation speed $(1000,1200 \mathrm{rpm})$ by appropriate selection of welding speed, but such experiment has not been conducted in the current investigation. The surface morphologies of produces joints are presented in Figure 3. Increasing of welding speed to the value of $800 \mathrm{~mm} / \mathrm{min}$ leads to insufficient heat input and weld defect. Although
Table 3. Designation and welding parameters of samples selected for further analysis.

\begin{tabular}{lll}
\hline $\begin{array}{l}\text { Sample } \\
\text { designation }\end{array}$ & $\begin{array}{l}\text { Tool rotation } \\
\text { speed }[\mathrm{rpm}]\end{array}$ & $\begin{array}{l}\text { Welding speed } \\
{[\mathrm{mm} / \mathrm{min}]}\end{array}$ \\
\hline Z41 & 400 & 100 \\
Z61 & 600 & 100 \\
Z81 & 800 & 100 \\
Z82 & 800 & 200 \\
Z84 & 800 & 400 \\
\hline
\end{tabular}

industrial applications seek to increase welding speed (reducing the time of production), we observed that for the low value $(100 \mathrm{~mm} / \mathrm{min})$ heat generated from the friction causes heating of material ahead of stirring zone entailing better clamping of elements to be weld due to thermal expansion. Basing on the surface morphology of obtained joints, the five welds have been selected for further analysis. The joints are set in Table 3.

\subsection{Macrostructure observations and microhardness analysis}

The images of joints macrostructure are presented in Figure 4. Imperfections in the form of voids are marked with yellow arrows. It can be observed that in all cases the used parameters formed the welds in the whole crosssections of workpieces and no incomplete root penetration type of imperfections are reported in the bottom part of the joints.

Macrostructure observations allow to notice a significant grain refinement in the stir zone, typical for FSW process. In the samples Z61 and Z82 (Fig. 4b,d) in the center part of the stir zone, it can be seen a characteristic grain structure, giving the impression of large grains. In fact, these structures of sub-grain nature are an effect of the geometric dynamic recrystallization phenomenon due to the presence of $\mathrm{Al}_{3}(\mathrm{Sc}, \mathrm{Zr})$ precipitates in the investigated alloy. The sub-grains structures are wider described by us in the research paper concerned with FSW of AA2519 in non-heat-treated condition [21]. Another observation is that the tool rotation speed plays a predominant role in the forming of stir zone shape. For the lower tool rotation speed (400 rpm) the stir zone is relatively wide with its boundary between thermo-mechanically affected zone of angular shape (Fig. 4a). By increasing of tool rotation speed (600, $800 \mathrm{rpm}$ ) the formed boundary between these zones becomes almost parallel to the tool axis, and the stir zones themselves are slightly narrower (Fig. 4b,c). At the same time, the samples produced by various welding speed are characterized by similar shape and size of the stir zone (Fig. 4c-e). It has to be noticed that despite the goodlooking weld face, the joints obtained with welding speed $200 \mathrm{~mm} / \mathrm{min}$ and more, have imperfections in form of voids in the upper part of the stir zone, close to the thermomechanically affected zone on the advancing side, marked with yellow arrows (Fig. $4 \mathrm{~d}, \mathrm{e}$ ). The participation of voids increasing together with welding speed and the value of 


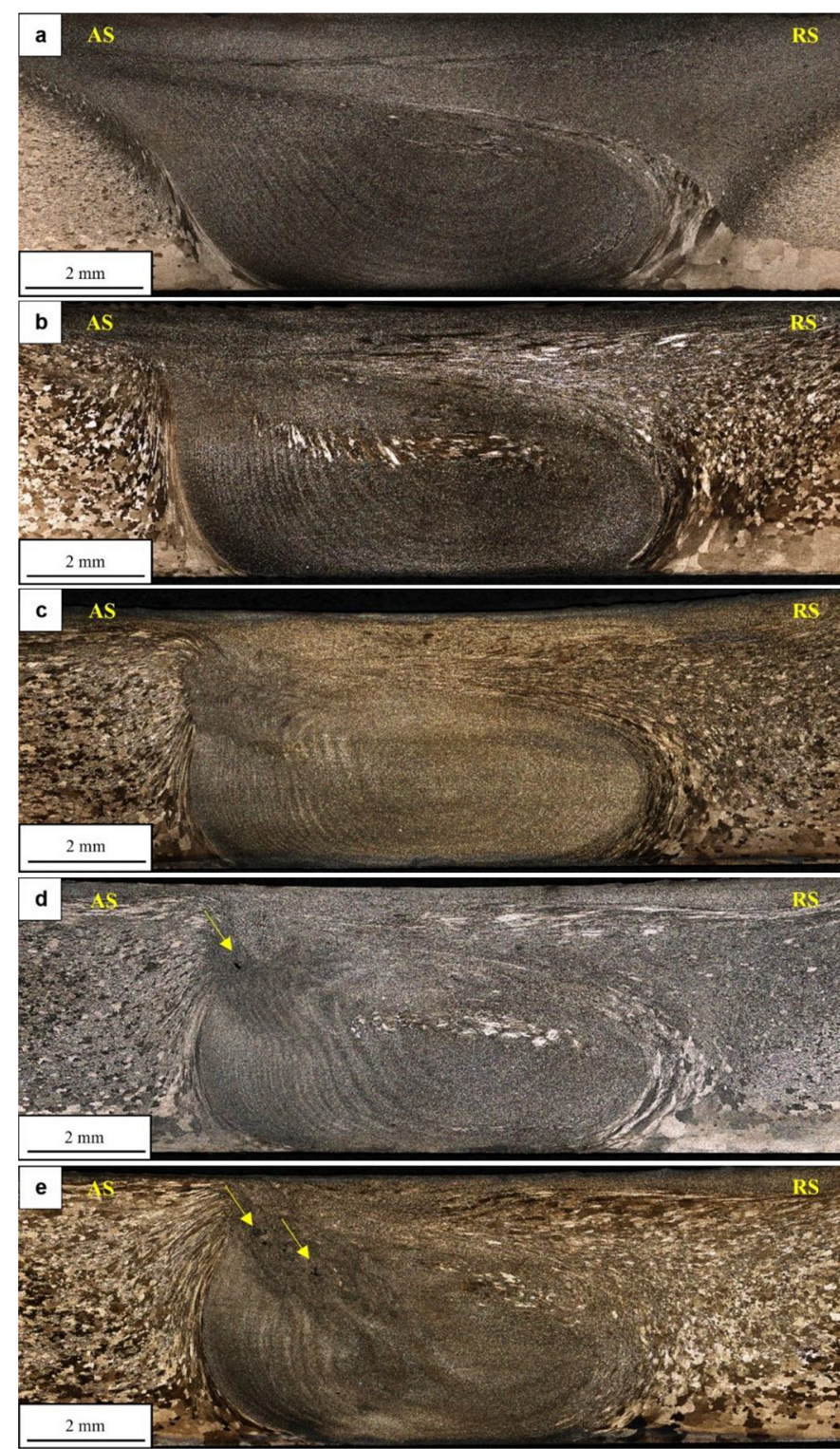

Fig. 4. Macrostructure of the joints: (a) Z41, (b) Z61, (c) Z81, (d) Z82, (e) Z84. AS - advancing side, RS - retreating side.

$800 \mathrm{~mm} / \mathrm{min}$ results in significant join defect in this area, visible on the weld face (Fig. 3). These results show that in the case of AA2519-T62 the set of parameters allowing obtaining a high-quality joint is relatively narrow, in contrast to far much softer non-heat treated AA2519 [21]. The void and cavity type of defects, which are present in Z82 and Z84 samples, can be formed by abnormal stirring. The phenomenon occurs at high values of both tool rotation and welding speed, what causes the differences in temperature between the top and bottom part of the welded workpiece resulting in discontinuities in the flow of the material [22]. In the previous study, the voids appeared in the same area during FSW of AA2519-O using $800 \mathrm{rpm}$ tool rotation speed, but only when welding speed was equal to $800 \mathrm{~mm} / \mathrm{min}$ [21]. The distributions of microhardness on the cross-section of the joints at the distance of $2.5 \mathrm{~mm}$

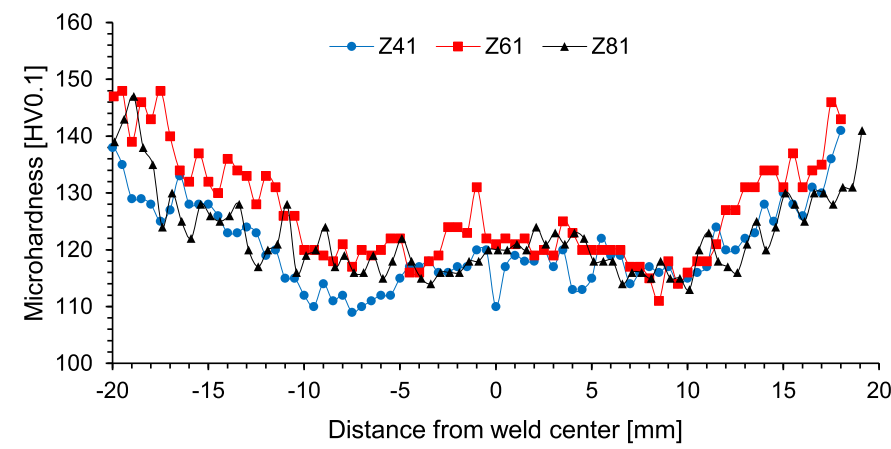

Fig. 5. Microhardness distribution for samples produced with constant welding speed of $100 \mathrm{~mm} / \mathrm{min}$. The negative values correspond to the advancing side.

from the top of the weld for samples Z41, Z61 and Z81 are presented in Figure 5.

As can be observed, the FSW process causes the reduction of microhardness in the welded area, what is directly connected to the dissolution of the strengthening phase [7]. In the stir zone, the reduction of microhardness is partly compensated by grain refinement. The visible spreads of microhardness are expected in the case of AA2519 for its high copper concentration $(6.3 \% \mathrm{Cu})$ results in the presence of large $\mathrm{Al}_{2} \mathrm{Cu}$ precipitates even after precipitation hardening process [23]. The stirring process decreases the microhardness from about 150 HV0.1 (value for base material) to about $125 \mathrm{HV} 0.1$ in the stir zone and to 115 HV0.1 in the heat-affected zone. For all samples produced by various values of tool rotation speed, the microhardness distribution has a similar character. Some differences are noticed in the stir zone, joint Z41 has a slightly lower value of microhardness than the other two samples, what can be explained by less efficient grain refinement due to lower value of tool rotation speed. This conclusion is supported by the observations of stir zones microstructure (Fig. 6a,b). The stir zone grain size of Z41 joint (Fig. 6a) is noticeably larger than in the case of Z81 joint (Fig. 6b) obtained by twice as high tool rotation speed. Similar observations on the relationship between tool rotation speed and microhardness and grain size in the stir zone have been reported in other investigations $[12,24,25]$.

Although each obtained line of microhardness shows a typical for FSW"W-shape" (for high-strength aluminum) it is difficult to draw evident conclusions about the influence of welding parameters on the microhardness in thermo-mechanically affected and heat-affected zones. It would be expected that increasing of tool rotation speed (so also a welding temperature) causes a noticeable softening of the material in these zones, but considering the fact that AA2519-T62 is used in partly pre-aged condition (for better ductility), the obtained results are not so obvious. The distributions of microhardness on the cross-section of the joints at the distance of $2.5 \mathrm{~mm}$ from the top of the weld for samples Z81, Z82 and Z84 are presented in Figure 7.

Analyzing the microhardness distributions of samples obtained with different welding speed it is possible to observe that microhardness of the stir zone is on an almost 

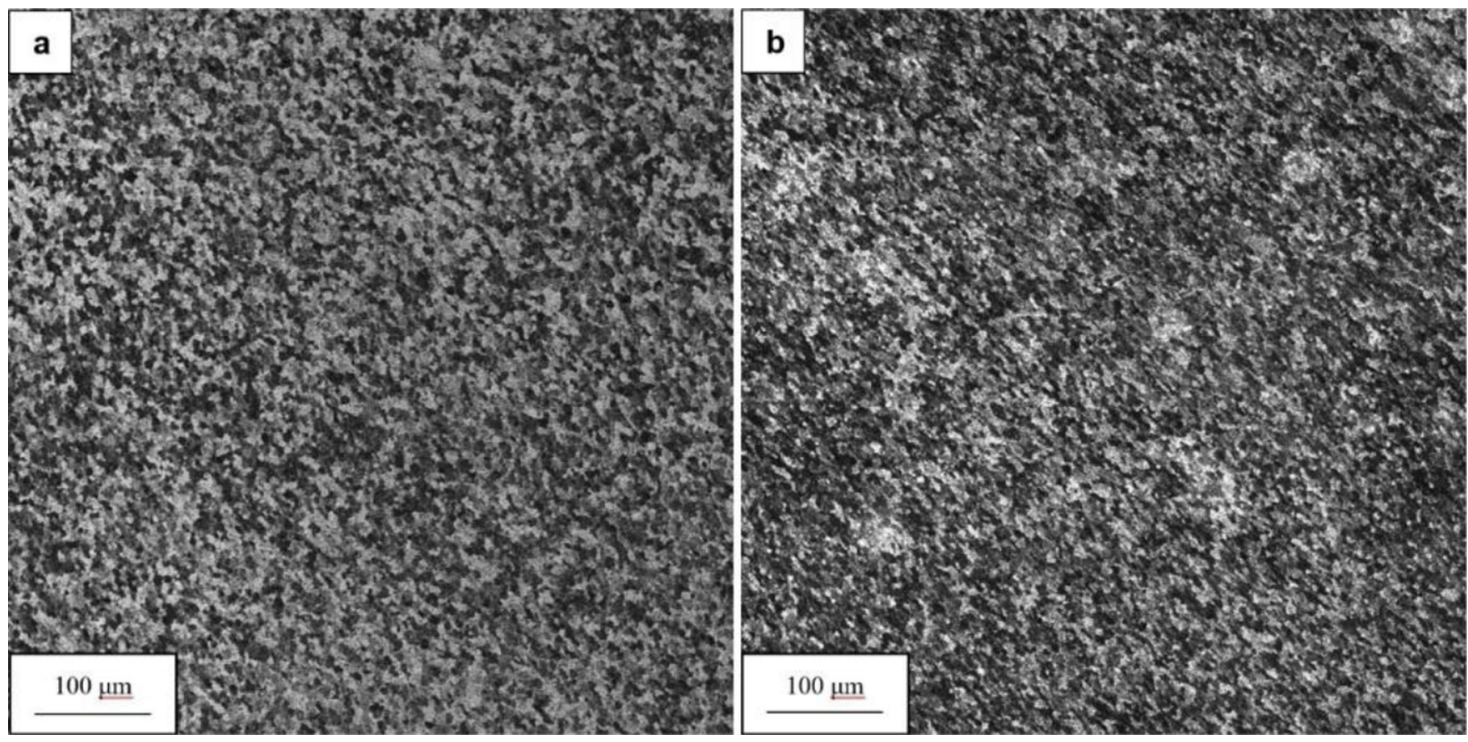

Fig. 6. The microstructure of the stir zone (a) Z41, (b) Z81.

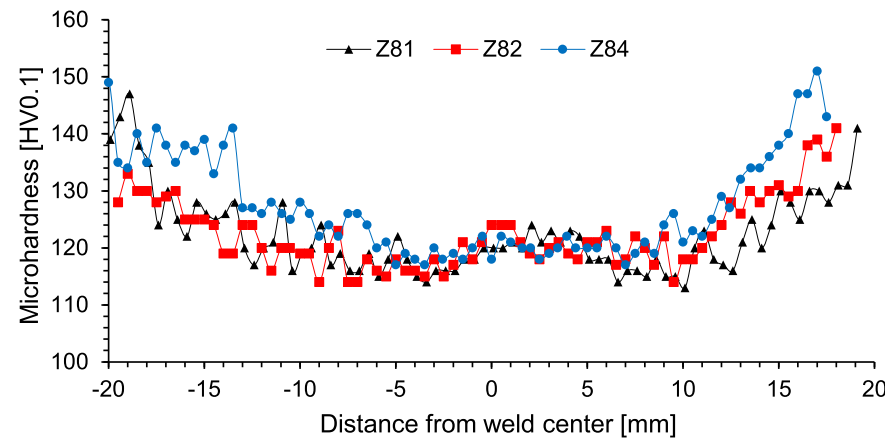

Fig. 7. Microhardness distribution for samples produced with constant tool rotation speed of $800 \mathrm{rpm}$. The negative values correspond to the advancing side.

identical level. At the same time, it is reported that increasing welding speed (so also decreasing of welding temperature) results in higher values of microhardness in thermo-mechanically affected and heat-affected zones. For sample Z84, the microhardness of these zones (about 120 HV0.1) is nearly equal to the stir zone value (about 125 HV0.1).

\subsection{Tensile test}

The representative curves obtained from tensile tests are presented in Figure 8. The established values of tensile strength, joint efficiency, and failure locations are set in Table 4.

The obtained curves indicate the good quality of the produced joints. The samples Z41 and Z61 exhibit very similar values of joint efficiency (close to 81\%). The noticeable increase in strength of the joint is observed in sample Z81 so as the reduction of elongation to break. An interesting result is that the highest reported value of joint efficiency (above 85\%) was reported for Z82 weld, which is characterized by the presence of small void imperfection in

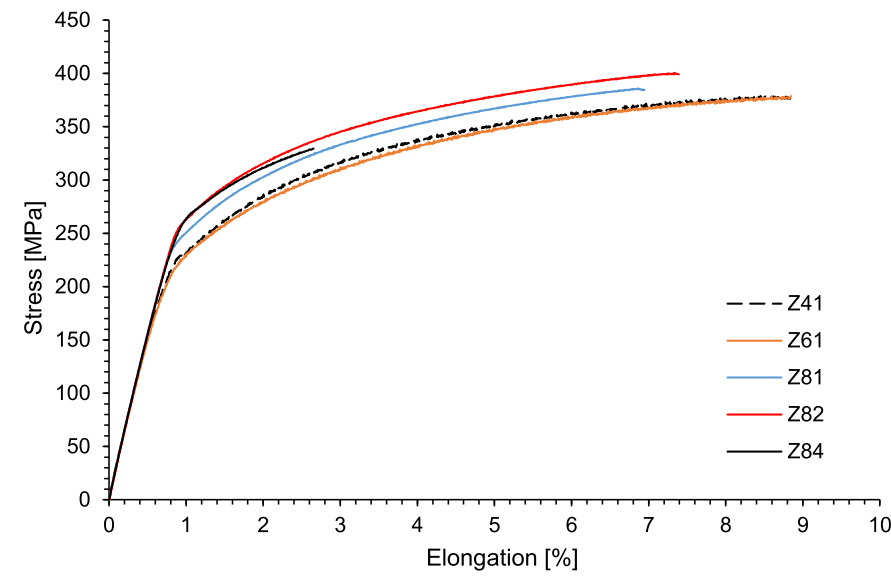

Fig. 8. The stress-strain curves of the investigated joints.

Table 4. The established values of tensile strength, joint efficiency, and failure location.

\begin{tabular}{lllll}
\hline Joint & $\begin{array}{l}\text { Tensile } \\
\text { strength } \\
{[\mathrm{MPa}]}\end{array}$ & $\begin{array}{l}\text { Standard } \\
\text { deviation } \\
{[\mathrm{MPa}]}\end{array}$ & $\begin{array}{l}\text { Joint } \\
\text { efficiency } \\
{[\%]}\end{array}$ & Failure \\
\hline Z41 & 382.3 & 3.95 & 80.9 & TMAZ (RS) \\
Z61 & 381.5 & 3.7 & 80.7 & TMAZ/SZ (AS) \\
Z81 & 387.7 & 2.2 & 82.3 & TMAZ/SZ (AS) \\
Z82 & 398.0 & 5.9 & 85.4 & TMAZ/SZ (AS) \\
Z84 & 316.0 & 26.5 & 70.2 & TMAZ/SZ (AS) \\
\hline
\end{tabular}

the rim of stir zone (Fig. 4d). Comparing the obtained values of joint efficiency with the results of the studies $[10,13]$, it can be stated that the obtained values of joint efficiency are very high as for high-strength aluminum alloy of 2XXX series, although it has to be taken under 

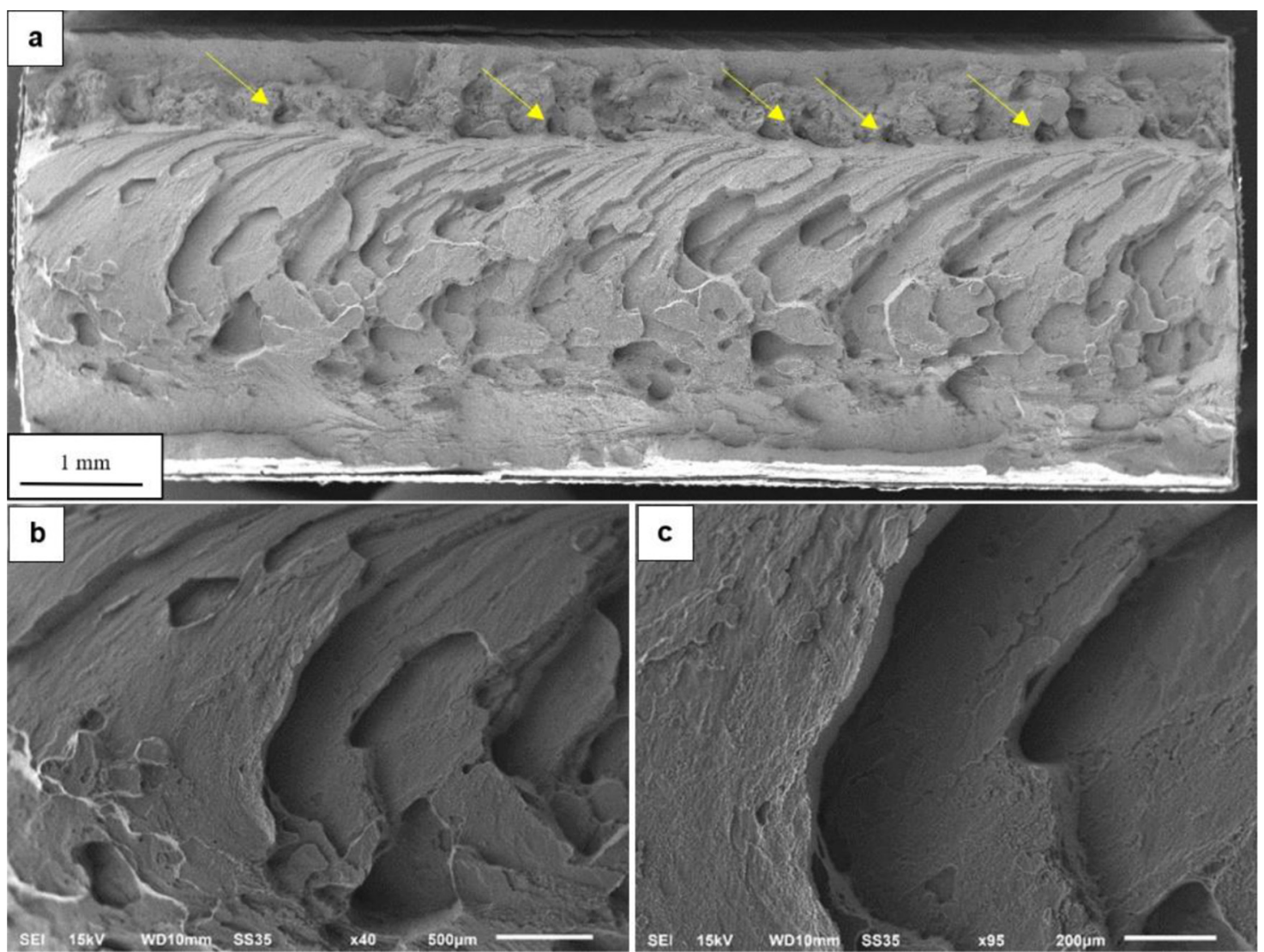

Fig. 9. The fracture surface of $\mathrm{Z} 84$ joint tensile sample (welding direction from left to right): (a) overall image with voids marked with yellow arrows, (b) stir zone surface, (c) flake-like structures on the stir zone.

consideration that in the current investigation the workpiece is much thicker $(5 \mathrm{~mm})$, what usually gives higher values of FSW joints tensile strength [5]. Despite the initial beneficial influence of increasing welding speed, the highest value of $800 \mathrm{~mm} / \mathrm{min}$ resulted in a relatively large decrease in joint efficiency to the lowest reported value of $70 \%$. This result suggests that only a substantial concentration of voids in the stir zone weakens the joint noticeably. Additionally, it is noteworthy that sample Z84 is characterized by the highest standard deviation of tensile strength. In most cases (except Z41 sample) the failure occurs at the boundary between thermo-mechanically affected zone and the stir zone on the advancing side of the weld. This phenomenon can be explained by one of the observations reported during macrostructure analysis. The 600 and $800 \mathrm{rpm}$ values of tool rotation speed form the boundary between TMAZ and SZ with compressed, elongated grains oriented parallel to the force applied in the tensile test (Fig. 4b-e). Although this specific structure determines the location of failure it cannot be identified as a defect, especially because the highest joint efficiency has been achieved for joints with this characteristic SZ/TMAZ boundary. The failure location is observed most distinctly in the sample Z84, the fracture surface of which is presented in Figure $9 \mathrm{a}-\mathrm{c}$.

In the fracture surface, it is possible to observe that a major part of the area is the stir zone interface (Fig. 9a). The upper part of the fracture surface is characterized by the presence of voids (marked with yellow arrows), which were identified during the macrostructure analysis of this sample (Fig. 4e). The stir zone interface visualizes the flow on the material in the FSW process with characteristic half-rings situated in accordance with the welding direction (Fig. 9b). It has been reported that these half-rings are the place of decohesion in the tensile test and delaminating layers of the material create flake-like structures on the surface of the stir zone (Fig. 9c).

\subsection{Low cycle fatigue properties at $\varepsilon=0.3 \%$}

The fatigue testing of the samples with constant true strain amplitude $\varepsilon=0.3 \%$ and the cycle asymmetry coefficient equal to $R=0.1$ allows to investigate the welded joints response to cyclic loading. The results presented in the curve of stress amplitude vs number of cycles (Fig. 10) shows that the obtained joints exhibit different characters of fatigue life. All analyzed samples underwent cyclic hardening during the initial phase of fatigue testing and then gained their cyclic stability until final failure. The very similar character of fatigue was observed for samples Z61 and Z81. At the same time, sample Z41 has a lower number of cycles to failure with significant cyclic hardening occurring its whole fatigue life. The samples having voids in their macrostructure $(\mathrm{Z} 82, \mathrm{Z} 84)$ are characterized by the lowest fatigue life in the performed tests. The sample Z84, 


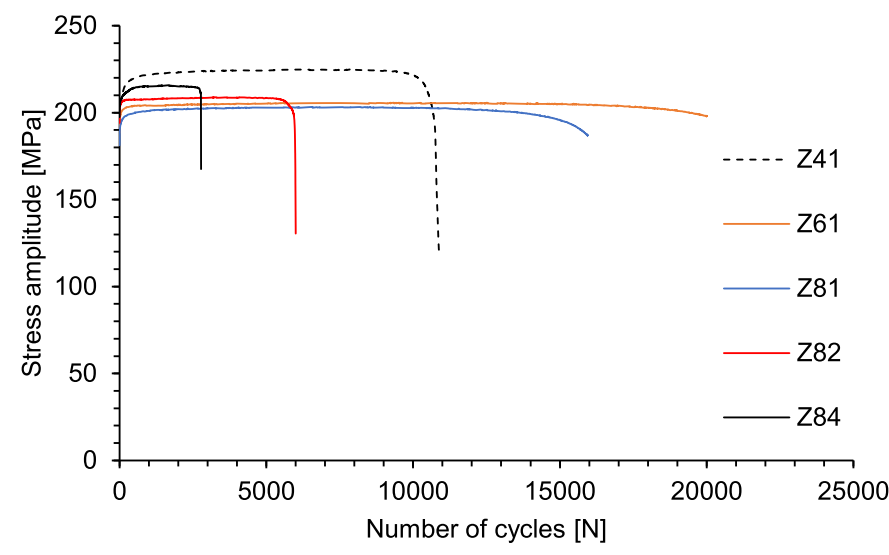

Fig. 10. Stress amplitude vs number of cycles at $\varepsilon=0.3 \%$.

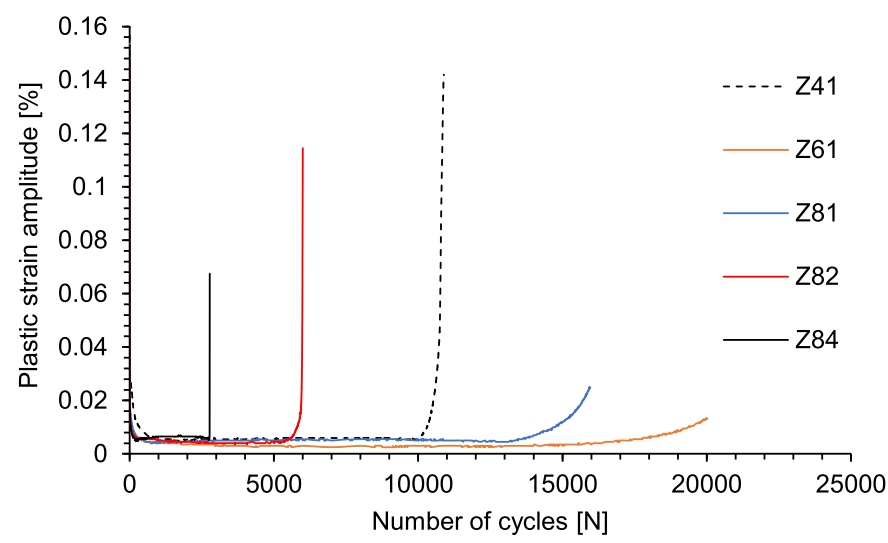

Fig. 11. Plastic strain amplitude vs number of cycles at $\varepsilon=0.3 \%$.

Table 5. The cycles to failure (to the nearest 100) and failure locations in the low cycle fatigue test.

\begin{tabular}{lll}
\hline Joint & Cycles to failure & Failure location \\
\hline Z41 & 10900 & SZ/TMAZ (RS) \\
Z61 & 20000 & SZ/TMAZ (RS) \\
Z81 & 16000 & HAZ (RS) \\
Z82 & 6000 & TMAZ/SZ (AS) \\
Z84 & 2800 & TMAZ/SZ (AS) \\
\hline
\end{tabular}

which given the lowest value of joint efficiency in the tensile test has the highest value of plastic strain amplitude from all analyzed joints (Fig. 11).

The failure locations of the investigated samples are set in Table 5. Generally, the major part of joints tends to fail on the SZ/TMAZ interface. It is noteworthy that every joint obtained with $100 \mathrm{~mm} / \mathrm{min}$ welding speed, regardless of tool rotation speed, has reached values above 10000 cycles to failure. For joints obtained with the lowest rotation speed values $(400,600 \mathrm{rpm})$ the fail took place on the retreating side of the $\mathrm{SZ}$ /TMAZ interface - in contrast to the joints Z82 and Z84, where the failure is located on the opposite side of the weld on the advancing side. The only exception is joint Z81 with failure located in the heataffected zone on the retreating side. Comparing to the advancing side, the retreating side is characterized by the highest heat input, what significantly reduces the strength of this area (especially in precipitate-hardened aluminum alloys) [26]. The heat causes a series of microstructural changes in HAZ including a coarsening of the strengthening phase and grain growth, which decrease the fatigue resistance and make crack propagation easier [27-29]. Especially the lowest hardness zone (LHZ), often became the failure location due to its both low hardness and high value of hardness gradient [12,27]. Although in the current investigation, the obtained microhardness distributions do not allow to clearly identify LHZ (Figs. 5 and 7), it can be estimated that sample Z81 is characterized by the highest heat input with all the fatigue resistance-decreasing microstructural changes, what can partly explain the failure in HAZ.

After fatigue testing, selected samples have been subjected to the observation of the fracture surface (Fig. 12a-d). The fracture surface of Z81 joint is very similar to the fracture surface of base material [30] and it contains typical fatigue striations with occurring secondary cracks (marked with yellow arrows) (Fig. 12a). The observations of samples Z82 and Z84 have confirmed that the presence of voids promotes the decohesion of material during fatigue testing and can be responsible for the location of failure on the advancing side of welds (Fig. 12b,d). Additionally, it has been reported that the fracture surface of the stir zone of Z84 joint contains bands with visible differences in the decohesion character (Fig. 12c), what can be partly connected to the phenomenon observed in the tensile sample surface (Fig. 9c).

\section{Conclusions}

The performed research on the influence of friction stir welding parameters on macrostructure and mechanical properties of Sc-modified AA2519-T62 allowed the following conclusions to be drawn:

- The joints obtained with welding speed of $100 \mathrm{~mm} / \mathrm{min}$ and tool rotation speed of $400-800 \mathrm{rpm}$ are of good quality - defect-free macrostructure and joint efficiency of about $80 \%$.

- Increasing welding speed with a constant tool rotation speed of $800 \mathrm{rpm}$ results in the formation of voids in the stir zone. The voids promote decohesion of welded material and drastically reduce the fatigue life of joints. Despite the presence of voids, joint Z82 has the highest joint efficiency above $85 \%$ but still has one of the weakest fatigue lives from all analyzed samples.

- Considering the results of macrostructure analysis, tensile, and low cycle fatigue (including failure location) it can be stated that the best set of welding parameters for AA2519-T62 is within the range of 600-800 rpm tool rotation speed with welding speed of $100 \mathrm{~mm} / \mathrm{min}$ for used MX Triflute tool. 

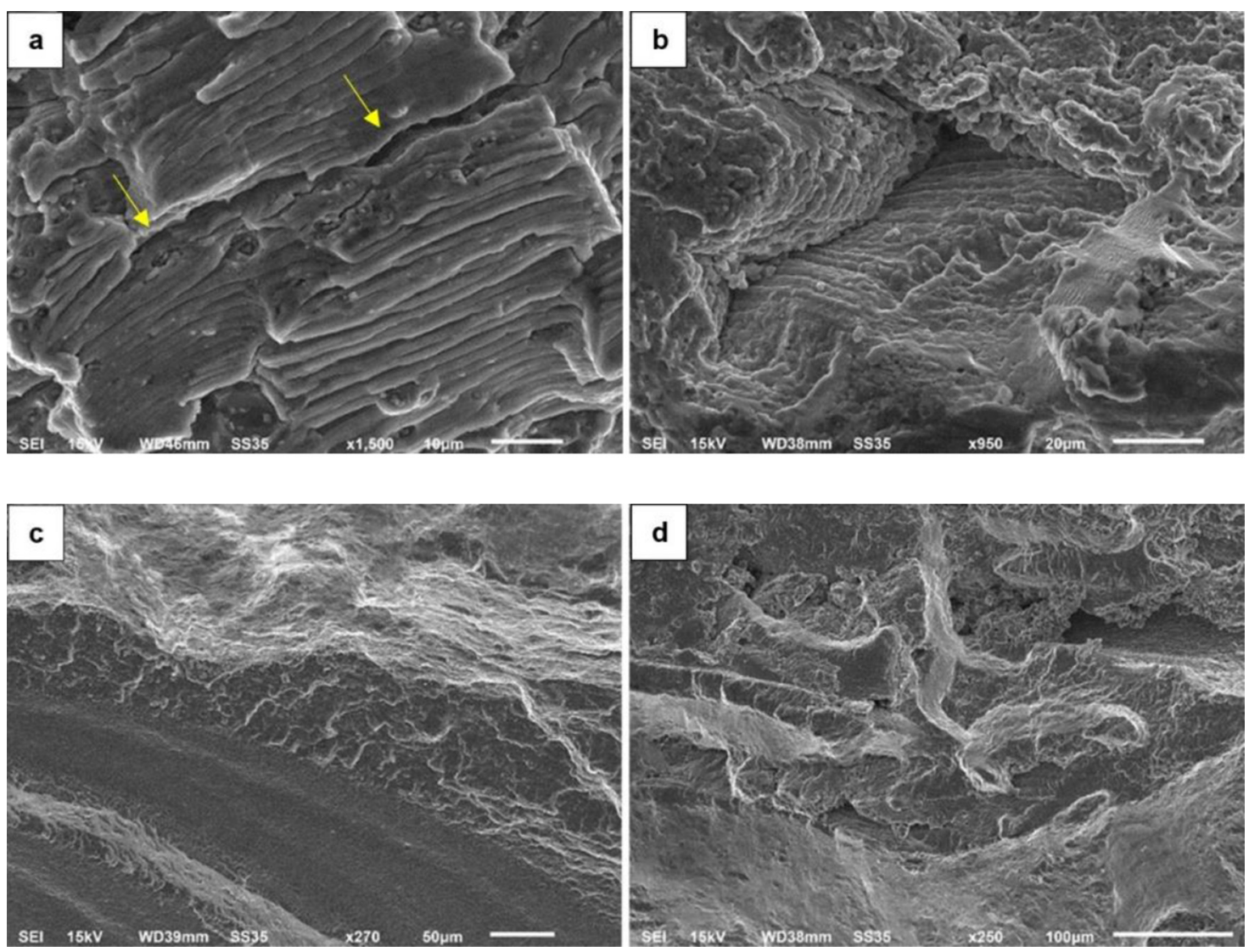

Fig. 12. The fracture surface of fatigue samples: (a) HAZ surface of Z81 joint; (b) TMAZ/SZ surface of Z82 joint, (c) TMAZ/SZ surface of Z84 joint, (d) TMAZ surface of Z84.

\section{Funding}

This research was funded by Polish Ministry of National Defence, grant number: PBG/13-998.

We would like to thank Dr Janusz Mierzynski for his helpful advice, constructive suggestions, and interesting observations during the selection of welding parameters.

\section{References}

1. Z.Y. Ma, A. Feng, D. Chen, J. Shen, Recent advances in friction stir welding/processing of aluminum alloys: microstructural evolution and mechanical properties, Crit. Rev. Solid State Mater. Sci. 43 (2017) 1-65

2. G. Çam, S. Mistikoglu, Recent developments in friction stir welding of Al-alloys, J. Mater. Eng. Perform 23 (2014) $1936-1953$

3. J. Kang, Z. Feng, G. Frankel, I. Huang, G. Wang, W. Aiping, Friction stir welding of Al alloy 2219-T8: Part I Evolution of precipitates and formation of abnormal $\mathrm{Al} 2 \mathrm{Cu}$ agglomerates, Metal. Mater. Trans. A 47A (2016) 9

4. V. Ch, G. Reddy, K. Rao, Influence of tool pin profile on microstructure and corrosion behaviour of AA2219 Al-Cu alloy friction stir weld nuggets, Defence Technol. 53 (2015) 197-208
5. R.S. Mishra, M.W. Mahoney, Friction Stir Welding and Processing (ASM International: Materials Park, OH, USA, 2007)

6. A. El-Morsy, M. Ghanem, H. Bahaitham, Effect of friction stir welding parameters on the microstructure and mechanical properties of AA2024-T4 aluminum alloy, Eng. Technol. Appl. Sci. Res. 8 (2018) 2493-2498

7. X. Liang, H. Li, Z. Li, T. Hong, B. Ma, S. Liu, Y. Liu, Study on the microstructure in a friction stir welded 2519-T87 Al alloy, Mater Des. 35 (2012) 603-608

8. G.H. Li, L. Zhou, S.F. Luo, Z.Y. Du, J.C. Feng, F.X. Meng, Microstructure and mechanical properties of self-reacting friction stir welded AA2219-T87 aluminium alloy, Sci. Technol. Weld. Joining 25 (2020) 142-149

9. M. Mijajlović, D. Milčić, Analytical model for estimating the amount of heat generated during friction stir welding: application on plates made of aluminium alloy 2024 T351, Welding Processes (2012) 247-274

10. S. Sabari, S. Malarvizhi, V. Balasubramanian, Characteristics of FSW and UWFSW joints of AA2519-T87 aluminium alloy: effect of tool rotation speed, J. Manuf. Process 22 (2016) 278-289

11. M. Ubaid, D. Baja, A.K. Mukhopadhyay, A. Siddiquee, Friction stir welding of thick AA2519 alloy: defect elimination, mechanical and micro-structural characterization, Met. Mater. Int. (2019) doi:10.1007/s12540-019-00472-3

12. Z. Zhang, B.L. Xiao, Z.Y. Ma, Effect of welding parameters on microstructure and mechanical properties of friction stir welded 2219Al-T6 joints, J. Mater. Sci. 47 (2012) 4075-4086 
13. H. Liu, H. Zhang, Q. Pan, Effect of friction stir welding parameters on microstructural characteristics and mechanical properties of 2219-T6 aluminum alloy joints, Int. J. Mater. Form 5 (2012) 235-241

14. W.F. Xu, J.H. Liu, D.L. Chen, Low-cycle fatigue of a friction stir welded 2219-T62 aluminum alloy at different welding parameters and cooling conditions, Int. J. Adv. Manuf. Technol. 74 (2014) 209-218

15. K. Subbaiah, G. Manivasagam, M. Govindaraju, S.R. Koteswara Rao, Mechanical properties of friction stir welded cast $\mathrm{Al}-\mathrm{Mg}-\mathrm{Sc}$ Alloys, Trans. Indian I Metals 65 (2012) 155-158

16. J. Chen, S. Li, H. Cong, Microstructure and mechanical behavior of friction stir-welded Sc-modified Al-Zn-Mg alloys made using different base metal tempers, J. Mater. Eng. Perform 28 (2019) 916-925

17. P. Cavaliere, Effect of minor Sc and $\mathrm{Zr}$ addition on the mechanical properties of friction stir processed 2024 aluminium alloy, J. Mater. Sci. 41 (2006) 4299-4302

18. V. Fedorchuk, I. Falchenko, Scandium influence on the structure and chemical inhomogeneity of welded joints of Al-Zn-Mg-Cu system alloys, Appl. Mech. Mater. 682 (2014) 464-468

19. V.E. Fedorchuk, Special features of the formation of the microstructure and chemical heterogeneity in welded joints in alloys of the $\mathrm{Al}-\mathrm{Zn}-\mathrm{Mg}-\mathrm{Cu}$ system alloyed with scandium, Weld. Int. 29 (2015) 619-623

20. C. Paglia, K. Jata, R. Buchheit, A cast 7050 friction stir weld with scandium: microstructure, corrosion and environmental assisted cracking, Mater. Sci. Eng. A 424 (2006) 196-204
21. R. Kosturek, L. Śnieżek, M. Torzewski, M. Wachowski, Research on the friction stir welding of Sc-modified AA2519 extrusion, Metals 9 (2019) 1-15

22. N. Dialami, M. Cervera, M. Chiumenti, Defect formation and material flow in friction stir welding, Eur. J. Mech. A 80 (2019) doi:10.1016/j.euromechsol.2019.103912.

23. J.E. Hatch, Aluminum: Properties and Physical Metallurgy (ASM International, West Conshohocken, PA, USA, 1984); ISBN 0871701766

24. Y. Li, D. Sun, W. Gong, Effect of tool rotational speed on the microstructure and mechanical properties of bobbin tool friction stir welded 6082-T6 aluminum alloy, Metals 9 (2019) 894

25. P. Kossakowski, W. Wcislik, M. Bakalarz, Effect of selected friction stir welding parameters on mechanical properties of joints, Arch. Civil Eng. 65 (2019) 51-62

26. A. Ravi Raja, M.Z. Yusufzai, M. Vashista, Characterization of advancing and retreating weld of friction stir welding of aluminium, in Proceedings of the ICAMM 2016, Bangkok, Thailand, 2016, 3-8

27. H. Li, J. Gao, Q. Li, Fatigue of friction stir welded aluminum alloy joints: a review, Appl. Sci. 8 (2018) 2626

28. J. Torzewski, K. Grzelak, M. Wachowski, R. Kosturek, Microstructure and low cycle fatigue properties of AA5083 H111 friction stir welded joint, Materials 13 (2020) 2381

29. M. Milčić, Z. Burzić, I. Radisavljević, T. Vuherer, D. Milčić, V. Grabulov, Experimental investigation of fatigue properties of FSW in AA2024-T351, Proc. Struct. Integr. 13 (2018) 1977-1984

30. R. Kosturek, L. Śnieżek, J. Torzewski, M. Wachowski, Low cycle fatigue properties of Sc-modified AA2519-T62 extrusion, Materials 13 (2020) 220

Cite this article as: Robert Kosturek, Lucjan Śnieżek, Janusz Torzewski, Marcin Wachowski, The influence of welding parameters on macrostructure and mechanical properties of Sc-modified AA2519-T62 FSW joints, Manufacturing Rev. 7, 28 (2020) 